\title{
The use of esketamine in comorbid
} treatment resistant depression and obsessive compulsive disorder following extensive pharmacogenomic testing: a case report

Marcatili Matteo ${ }^{1,2^{*}} \mathbb{0}$, Pellicioli Cristian², Maggioni Laura ${ }^{2}$, Motta Federico ${ }^{2}$, Redaelli Chiara ${ }^{2}$, Ghelfi Lorenzo ${ }^{3}$, Krivosova Michaela, Matteo Sibilla², Nava Roberto' , Colmegna Fabrizia', Dakanalis Antonios², Caldiroli Alice ${ }^{1}$, Capuzzi Enrico', Benatti Beatrice ${ }^{5,6}$, Bertola Francesca ${ }^{7}$, Villa Nicoletta7, Piperno Alberto ${ }^{2,7}$, Ippolito Silvia ${ }^{8}$ and Clerici Massimo ${ }^{1,2}$

\begin{abstract}
Background: Major depressive disorder (MDD) patients not responding to two or more different antidepressant treatments are currently considered to suffer from treatment resistant depression (TRD). Recently, intranasal esketamine has been approved by both the American Food and Drug Administration and European Medicines Agency for TRD and, more recently, in moderate to severe episode of MDD, as acute short-term treatment for the rapid reduction of depressive symptoms, which, according to clinical judgement, constitute a psychiatric emergency. There is currently no indication for obsessive-compulsive disorder (OCD) although recently published studies have already shown a rapid and significant reduction of OCD-like symptoms following ketamine administration. The etiology of OCD has not yet been fully elucidated but there is a growing evidence that glutamate signaling dysfunction in the cortico-striatal-thalamo-cortical circuitry plays an essential role. This case report exemplifies possible clinical effects of esketamine on both depressive and OCD symptoms.

Case presentation: We present the case of a 39-year-old man suffering from TRD. During the first evaluation at our clinic, he also reported the presence of OCD spectrum symptoms, causing him to perform time-consuming mental rituals due to pathological doubts regarding the relationship with his wife as well as intrusive thoughts regarding his mental conditions. He underwent psychometric evaluations, therapeutic drug monitoring analysis, and pharmacogenomic tests. The overall results helped to explain patient's treatment-resistance. Moreover, we observed a significant reduction in both depressive and OCD symptoms after administration of esketamine.
\end{abstract}

Conclusion: This case underlines the importance of pharmacogenomic tests in profiling TRD patients and confirms the possible use of esketamine in the treatment of comorbid OCD.

Keywords: Treatment resistant depression, TRD, Obsessive-compulsive disorder, OCD, Esketamine, Ketamine, SLC6A4, MTHFR, GABRP, GABRA6

*Correspondence: m.marcatili@asst-monza.it

2 Department of Medicine and Surgery, University of Milano Bicocca, Monza, Italy

Full list of author information is available at the end of the article

\section{Background}

Major depressive disorder (MDD) is a common mental disorder and a leading cause of disability, affecting more than 264 million people worldwide $[1,2]$. 
The STAR*D study demonstrated that only one third of patients achieved remission following the first antidepressant treatment and, even after 1 year of therapy with a sequence of four antidepressants administered for 12 weeks each, only two-third of patients achieved symptoms remission [3]. Although no single definition of treatment resistant depression (TRD) exists, it generally indicates patients who failed to respond to two or more trials of antidepressants, at adequate dosage and treatment duration [4]. As TRD patients seem not to respond sufficiently to traditional monoaminergic antidepressants, new treatment strategies acting on glutamatergic, cholinergic, and opioid systems are currently under investigation [5]. Pharmacogenomic testing (PGx) represents a decision-support tool that has been recently introduced into the clinical practice in psychiatry. Such personalized approach is especially useful in patients with conditions resistant to standard treatments due to genetic predisposition to poor psychopharmacological response or high susceptibility to severe side effects. PGx has several benefits: it could both lower the latency to clinical response or remission and increase patient's compliance by reducing side effects impact and cost-effectiveness of the whole clinical management. The comorbidity of depression with other psychiatric disorders has been described in the past, and one of the most common comorbidities is represented by Obsessive-Compulsive Disorder (OCD) [6-8]. The coexistence of the two disorders seems to lead to a greater symptoms severity, less satisfactory response to treatment and an overall less favorable prognosis [8]. The disorders share common psychopathological characteristics and, in some cases, also treatment response [9-11]. Dysregulation of glutamate signaling in the cortico-striatal-thalamo-cortical circuitry appears to play a role in OCD as supported by preclinical, neuroimaging, and genetic studies [12-18].

Intranasal esketamine has been approved by both the American Food and Drug Administration and the European Medicines Agency for TRD in adults and, more recently, in moderate to severe episode of MDD, as acute short-term treatment for the rapid reduction of depressive symptoms, which according to clinical judgement constitute a psychiatric emergency. Esketamine is the (S) enantiomer of ketamine, a non-competitive $\mathrm{N}$-methyl$\mathrm{D}$-aspartate (NMDA) glutamate receptor antagonist that was introduced in clinics as an anesthetic and analgesic more than 50 years ago $[19,20]$. The mechanism of antidepressant action of esketamine has not been fully clarified yet but modulation of different signaling pathways implicated in the pathophysiology of MDD, such as synaptogenesis and neuroplasticity pathways, may play a role [21, 22]. Although off-label, encouraging results have emerged from the use of intravenous ketamine in treatment resistant OCD as reported by previous clinical studies and case reports [23-26], hence the growing interest in the use of intranasal esketamine in treatment resistant $\mathrm{OCD}$.

The aims of this case report were to support the role of pharmacogenomic testing in psychiatry, especially in TRD patients, and to evaluate the effects of intranasal esketamine in the treatment of TRD with comorbid OCD.

\section{Case presentation}

We hereby present the case of M.G., a 39-year-old male married engineer, who presented at our clinic for a major depressive episode in the context of a TRD. He had a positive psychiatric family history, since his mother suffered from MDD, while his father had an alcohol use disorder.

MDD onset in this patient had occurred at the age of 27 , with a substantial recovery with the introduction of sertraline $(50 \mathrm{mg} /$ day $)$ in combination with psychodynamic psychotherapy.

Despite a long disease-free period, in 2019, after his first son's birth, M.G. experienced a relapse of MDD, characterized by a significant mood deflection, emotional lability, and severe fatigue. Hence, multiple pharmacological trials were made (Table 1 ), with only partial benefit (Fig. 1).

In November 2020, due to the persistence of depressive symptoms, M.G. was referred to our Treatment-Resistant Disorders Clinic at San Gerardo Hospital, Monza, Italy by his private psychiatrist. During our first assessment, M.G. reported the persistence of anhedonia, low energy, asthenia, remarkable levels of anxiety and cognitive impairment (e.g.: persistent poor concentration and attentional deficits), which led to poor performance at work. The patient also reported to be emotionally detached from his family, friends, and environment.

Together with typical MDD symptoms, M.G. showed disabling symptoms related to OCD spectrum that led to the additional diagnosis of OCD according to the DSM-5 criteria $[27,28]$.

Indeed, over the last 2 years the patient had developed intrusive and egodystonic obsessions, consisting mainly in pathological doubts regarding his wife. Specifically, even if physically attracted to his partner, he felt forced to spend a considerable amount of time engaged in mental rituals, consisting of repetitively glancing at his partner to check her body features, such as her nose or chin and subsequently questioning himself about the meaning of these compulsions (e.g.: "Am I continuously checking her chin or nose because I don't love her anymore?", "I like her, so why do I have so many doubts about her?"). Such obsessive preoccupations, intrusive thoughts and rituals 
Table 1 Psychopharmacological history

\begin{tabular}{|c|c|c|c|c|}
\hline Year & Medication & Dose & Duration & Notes \\
\hline 2013 & Sertraline & $50 \mathrm{mg}$ & 5 years & Recovery (primary treatment) \\
\hline 2018 & Sertraline & $200 \mathrm{mg}$ & 6 months & Partial response (primary treatment) \\
\hline $03 / 2019$ & Risperidone & $2 \mathrm{mg}$ & 2 months & Stopped because of cognitive impairment (augmentation) \\
\hline 05/2019 & Aripiprazole & $5 \mathrm{mg}$ & 5 months & Stopped because of cognitive impairment (augmentation) \\
\hline $10 / 2019$ & Paroxetine & $40 \mathrm{mg}$ & 6 months & No response (primary treatment, switched from Sertraline) \\
\hline $10 / 2019$ & Bupropion & $300 \mathrm{mg}$ & Ongoing & Partial response (combination) \\
\hline $01 / 2020$ & Olanzapine & $5 \mathrm{mg}$ & Ongoing & Partial response (combination) \\
\hline $01 / 2020$ & Lamotrigine & $150 \mathrm{mg}$ & Ongoing & Partial response (primary treatment) \\
\hline 06/2020 & Venlafaxine & $225 \mathrm{mg}$ & Ongoing & Partial response (primary treatment) \\
\hline
\end{tabular}

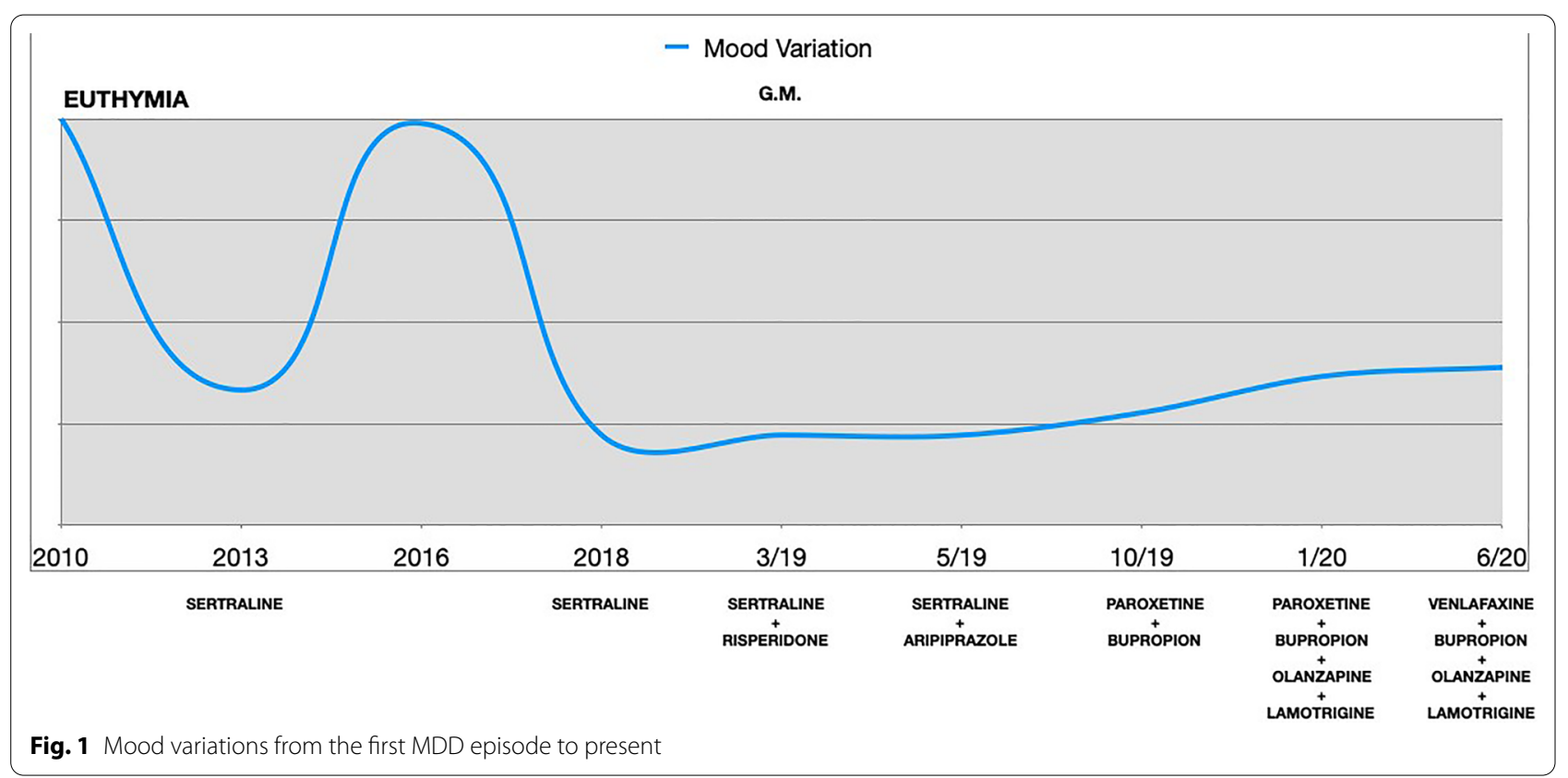

are what is commonly referred to as relationship obsessive-compulsive disorder $[8,29]$.

In addition, he also reported the presence of ritualistic intrusive and pervasive doubts regarding his mental health conditions. This implied the need to perform time-consuming mental rituals every morning (e.g.: independently from his psychopathological state, he used to repeat analytic checklists monitoring his conditions with precise order: "Am I feeling alright?", "Am I depressed?", “Am I happy?", “Why did I cry?", "Is it depression or something else?", "If I feel I have little strength, does it mean that I am depressed?").

When M.G. first came to our clinic, his therapy consisted of venlafaxine $225 \mathrm{mg} / \mathrm{die}$, bupropion $300 \mathrm{mg} /$ die, lamotrigine $150 \mathrm{mg} / \mathrm{die}$, and olanzapine $5 \mathrm{mg} / \mathrm{die}$.
Table 2 Psychometric assessment at first consultation

\begin{tabular}{lc}
\hline Rating scale & Score \\
\hline BPRS & 27 \\
MADRS & 15 \\
YBOCS & 15 \\
CGI-S & 3 \\
\hline
\end{tabular}

BPRS Brief Psychiatric Rating Scale, MADRS Montgomery-Åsberg Depression Rating Scale, YBOCS Yale-Brown obsessive-compulsive scale, CGI-S clinical global impression-severity

In line with our Treatment-Resistant Disorders clinic protocol, clinical consultation, psychometric assessment (Table 2), Therapeutic Drug Monitoring (TDM) (Table 3) and Pharmacogenomic analysis were performed (Table 4). 
Table 3 Therapeutic drug monitoring of venlafaxine at first consultation

\begin{tabular}{lll}
\hline Medication & Blood level & Therapeutic range* \\
\hline Venlafaxine & $484.5 \mathrm{ng} / \mathrm{mL}$ & $100-400 \mathrm{ng} / \mathrm{mL}$ \\
\hline
\end{tabular}

Serum level of venlafaxine is measured as a level of venlafaxine active moiety (venlafaxine + 0-desmethylvenlafaxine). Method: LC-MS (Liquid chromatography-mass spectrometry). *According to Hiemke et al. [30]

Even though the patient resulted to have moderate depressive and obsessive symptomatology at psychometric evaluations, the patient's quality of life was deeply affected, as he suffered from frequent crying fits, inability to concentrate at work and to engage in leisurable activities. Following the clinical interview, the patient was diagnosed with TRD with OCD symptoms and enrolled for intranasal esketamine treatment. A standard administration scheme was followed (Table 5), maintaining current patient treatment.

As a result of esketamine introduction, the patient showed a rapid resolution of depressive symptoms during the induction phase and a significant reduction of OCD symptoms during the maintenance phase (Fig. 2).

By the time of the ninth esketamine administration, in consideration of the evident clinical improvement, olanzapine and lamotrigine were stopped after appropriate tapering. Some residual anxious symptoms were managed thanks to the introduction of pregabalin titrated up to $225 \mathrm{mg}$ /die with further clinical benefit.

\section{Conclusions and discussion}

The present case report emphasizes the need for thorough diagnostic investigation to optimize the management of treatment-resistant cases. Indeed, TDM and genetic profiling are of relevant importance to determine optimal treatment.

In this case, serum levels of venlafaxine were $484.4 \mathrm{ng} /$ $\mathrm{mL}$, which is above the therapeutic range according to the TDM guidelines in neuropsychopharmacology [30]. Thus, the abnormal biotransformation of the drug was not considered as an explanation for the treatment resistance.

Considering the results of pharmacogenomic analysis, the presence of 2 common single nucleotide polymorphisms in methylenetetrahydrofolate reductase (MTHFR) gene in this patient, specifically C677T and A1298C, might have contributed to his vulnerability to psychiatric disorders. MTHFR is an enzyme catalyzing the conversion of folic acid into its active form, methylfolate, which plays an essential role in monoamine biosynthesis [31]. T allele in C677T and C allele in A1298C might lead to decreased enzymatic activity, thus, as
Table 4 Pharmacodynamic (A) and pharmacokinetic (B) gene variations

\begin{tabular}{|c|c|}
\hline Gene & Genotype \\
\hline \multicolumn{2}{|l|}{ (A) } \\
\hline $\begin{array}{l}\text { SLC6A4 } \\
\text { (rs63749047; } \\
\text { rs25531) }\end{array}$ & $\begin{array}{l}\text { S/S } \\
\text { [Low activity] }\end{array}$ \\
\hline $\begin{array}{l}\text { MTHFR } \\
\text { (rs1801133; } \\
\text { rs1801131) }\end{array}$ & $\begin{array}{l}\text { C677T: C/T } \\
\text { A1298C: A/C } \\
\text { [Low to intermediate activity] }\end{array}$ \\
\hline $\begin{array}{l}\text { ADRA2A } \\
\text { (rs1800544) }\end{array}$ & $\begin{array}{l}\text { C/G } \\
\text { [Improved response] }\end{array}$ \\
\hline $\begin{array}{l}\text { HTR2A } \\
\text { (rs7997012) }\end{array}$ & $\begin{array}{l}\text { G/A } \\
\text { [Normal response] }\end{array}$ \\
\hline $\begin{array}{l}\text { BDNF } \\
(\text { rs6265) }\end{array}$ & $\begin{array}{l}\text { Val/Nal } \\
\text { [Normal activity] }\end{array}$ \\
\hline $\begin{array}{l}\text { COMT } \\
(\mathrm{r} s 4680)\end{array}$ & $\begin{array}{l}\text { Val/Met } \\
\text { [Normal activity] }\end{array}$ \\
\hline HLA-A *31:01 & $\begin{array}{l}\text { Negative } \\
\text { [Normal] }\end{array}$ \\
\hline HLA-B *15:02 & $\begin{array}{l}\text { Negative } \\
\text { [Normal] }\end{array}$ \\
\hline $\begin{array}{l}\text { DRD2 } \\
\text { (rs1799732) }\end{array}$ & $\begin{array}{l}\mathrm{C} / \mathrm{C} \\
\text { [Normal activity] }\end{array}$ \\
\hline $\begin{array}{l}\text { MC4R } \\
\text { (rs489693) }\end{array}$ & $\begin{array}{l}\mathrm{C} / \mathrm{A} \\
\text { [Normal activity] }\end{array}$ \\
\hline $\begin{array}{l}\text { 5HT2C } \\
\text { (rs3813929) }\end{array}$ & $\begin{array}{l}\text { C/C } \\
\text { [Standard weight gain risk] }\end{array}$ \\
\hline $\begin{array}{l}\text { ANK3 } \\
\text { (rs10994336) }\end{array}$ & $\begin{array}{l}\mathrm{C} / \mathrm{C} \\
{[\text { Normal activity] }}\end{array}$ \\
\hline $\begin{array}{l}\text { CACNA1C } \\
\text { (rs1006737) }\end{array}$ & $\begin{array}{l}\mathrm{G} / \mathrm{G} \\
{[\text { Normal activity] }}\end{array}$ \\
\hline $\begin{array}{l}\text { OPRM1 } \\
\text { (rs1799971) }\end{array}$ & $\begin{array}{l}\text { A/A } \\
\text { [Normal activity] }\end{array}$ \\
\hline $\begin{array}{l}\text { GRIK1 } \\
\text { (rs2832407) }\end{array}$ & $\begin{array}{l}\text { A/A } \\
\text { [Normal activity] }\end{array}$ \\
\hline $\begin{array}{l}\text { GABRA6 } \\
\text { (rs3219151) }\end{array}$ & $\begin{array}{l}\mathrm{T} / \mathrm{T} \\
{[\text { Increased risk] }}\end{array}$ \\
\hline $\begin{array}{l}\text { GABRP } \\
(\mathrm{rs} 10036156)\end{array}$ & $\begin{array}{l}\mathrm{T} / \mathrm{T} \\
\text { [Increased risk] }\end{array}$ \\
\hline \multicolumn{2}{|l|}{ (B) } \\
\hline CYP2B6 & $\begin{array}{l}{ }^{*} 4 /{ }^{* 5} \\
\text { RM } \\
\text { [High activity] }\end{array}$ \\
\hline CYP2C19 & $\begin{array}{l}{ }^{*} /{ }^{*} 17 \\
\text { RM } \\
{[\text { High activity }]}\end{array}$ \\
\hline CYP2D6 & $\begin{array}{l}{ }^{*} 2 /{ }^{*} 4 \\
\text { IM } \\
\text { [Intermediate activity] }\end{array}$ \\
\hline $\begin{array}{l}\text { UGT2B15 } \\
\text { (rs1902023) }\end{array}$ & $\begin{array}{l}{ }^{*} 2 /{ }^{*} 2 \\
\text { IM } \\
\text { [Decreased activity] }\end{array}$ \\
\hline CYP1A2 & $\begin{array}{l}{ }^{* 1} \mathrm{~A} / \mathrm{H} 8 \\
\mathrm{EM} \\
{[\text { Normal activity] }}\end{array}$ \\
\hline CYP2C9 & $\begin{array}{l}{ }^{* 1} 1 /{ }^{*} 1 \\
\text { EM } \\
{[\text { Normal activity] }}\end{array}$ \\
\hline
\end{tabular}


Table 4 (continued)

\begin{tabular}{ll}
\hline Gene & Genotype \\
\hline CYP3A4 & ${ }^{*} 1 /{ }^{* 1}$ \\
& EM \\
& {$[$ Normal activity] } \\
UGT1A4 & ${ }^{* 1 a} /{ }^{*} 1 \mathrm{a}$ \\
$(\mathrm{rs} 2011425)$ & EM \\
& {$[$ Normal activity] } \\
ABCB1 & A/A \\
(rs2032583) & {$[$ Normal activity] } \\
ABCB1 & G/G \\
(rs1045642) & {$[$ Normal activity $]$} \\
\hline
\end{tabular}

In the table pharmacodynamic as well as pharmacokinetic gene polymorphisms are listed along with a brief interpretation. $R M$ rapid metabolizer, $E M$ extensive (normal) metabolizer, $I M$ intermediate metabolizer

Table 5 Esketamine administration scheme

\begin{tabular}{llll}
\hline Phase & Period & $\begin{array}{l}\text { Frequency of } \\
\text { administration }\end{array}$ & Dose \\
\hline Induction & First month & 2 times/week & $56 \mathrm{mg}$ \\
Maintenance & Second month & 1 time/week & $56 \mathrm{mg}$ \\
Maintenance & Third month and longer & 1 time/2 weeks & $56 \mathrm{mg}$ \\
\hline
\end{tabular}

previously reported, an increased risk of affective disorders, such as MDD or other psychiatric disorders [32-34].

In addition, the genetic profiling also showed the $\mathrm{S} / \mathrm{S}$ 5-HTTLPR genotype in SLC6A4 gene. SLC6A4 is a serotonin transporter responsible for serotonin reuptake. Such variations ( $s$ allele), previously described in the literature, are linked to decreased serotonin transporter expression in neurons, leading to higher susceptibility to depression, as well as poorer response to Selective serotonin reuptake inhibitors (SSRIs) [35-38]. This might also explain the patient's non-response to previous treatments with first-line antidepressants.

A prominent role in the brain control of stress plays GABA [39]. GABRA6 gene encodes the alpha6 subunit of GABA-A receptor and, according to previous studies, when exposed to recent negative stressful events, $\mathrm{T}$ allele carriers were at greater risk of depression- and anxiety-related symptoms which could also enhance suicidal risk [40]. Another study looked at the different types of recent life stressors and found that $\mathrm{T} / \mathrm{T}$ genotype in patients, which was present in this case, interacts significantly with recent illness and personal

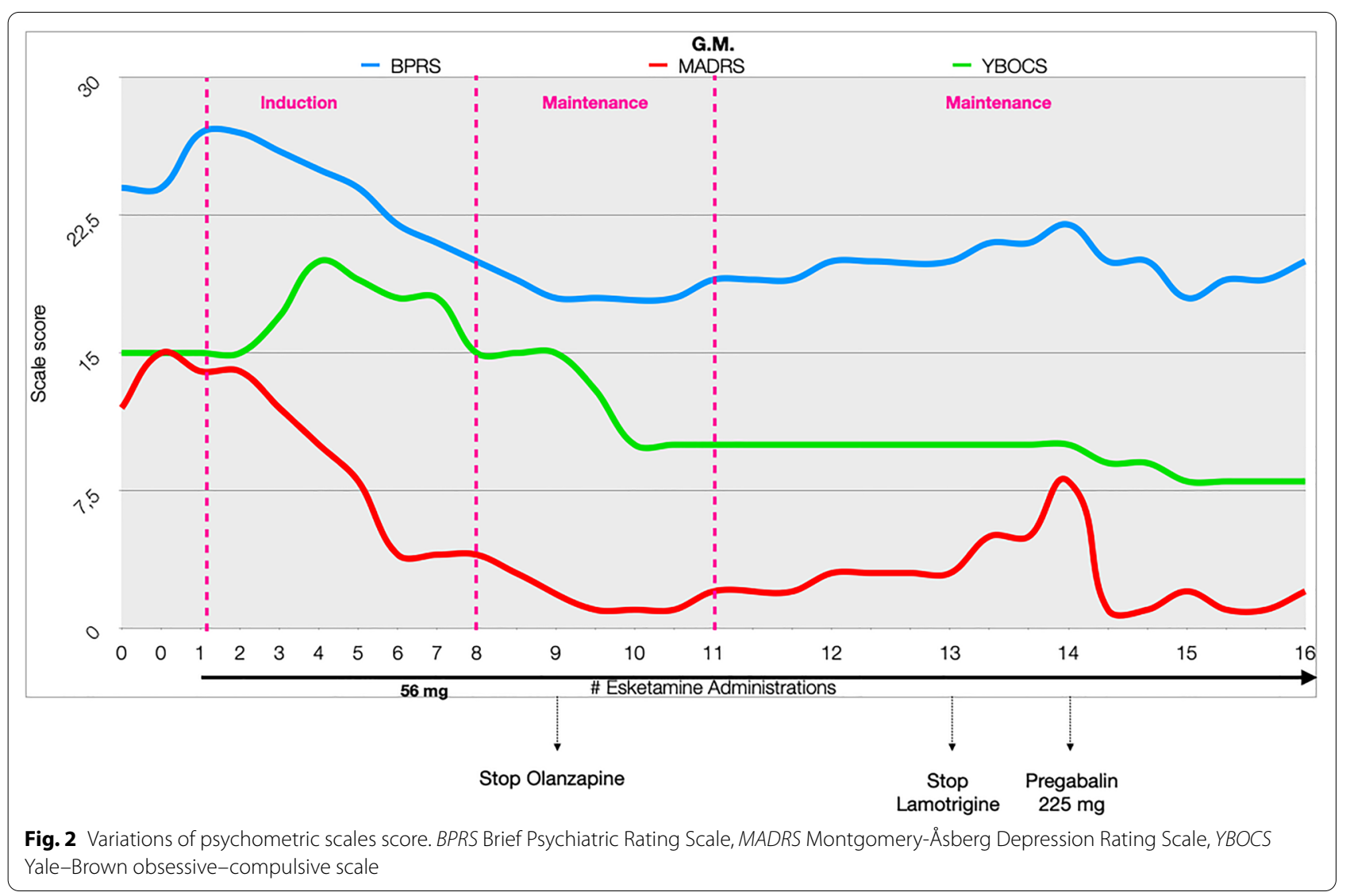


problems stressors in influencing depression [41]. C allele carriers of another gene related to GABA, pi subunit of the GABA-A receptor (GABRP), were associated with good response to single antidepressant (either SSRI or venlafaxine) administered for at least 6 weeks [42]. In our patient the T/T genotype was found, representing a possible factor to his treatment refractoriness.

In addition, the patient was a CYP2B6 and CYP2C19 rapid metabolizer, potentially contributing to the inefficacy of bupropion and other SSRI. The predominant metabolic pathway of bupropion that leads to formation of its active metabolite hydroxybupropion is CYP2B6 enzyme-mediated. In case of rapid metabolizers, the therapeutic outcome of bupropion therapy is strongly affected [43].

Moreover, this case not only validates the rapidity of esketamine in reverting depressive symptoms, but it also shows encouraging findings about the possible use of esketamine in treating OCD symptoms.

Indeed, during the maintenance phase, the patient showed a significant reduction in his OCD symptomatology as showed by the Yale-Brown Obsessive-Compulsive Disorder (YBOCS) score reduction (Fig. 2, green line): after initial symptoms' worsening due to a new-onset pathological doubt regarding treatment efficacy and side effects, the YBOCS score showed a $46.67 \%$ reduction (from 15 to 8 ). Since the pre-existing pharmacological treatment was not changed at our clinic, the reduction of the OCD symptoms might be directly referred to the use of esketamine.

It is worth noting that the time-ratio required to relieve OCD symptomatology maintained the 3:1 ratio usually seen with the use of serotonergic antidepressants $[44,45]$.

Literature regarding the possible use of ketamine in OCD remains sparse with some pre-clinical [46] and clinical studies $[25,26]$ showing a rapid reduction of OCD symptoms after the drug administration. Specifically, human studies indicated that ketamine could quickly and transiently decrease OCD behaviors. Nonetheless, these studies showed multiple limitations, mainly regarding small sample sizes and short-term observations. Thus, further investigation in the form of double-blind, randomized controlled trials is warranted.

\begin{abstract}
Abbreviations
MDD: Major depressive disorder; NMDA: N-Methyl-D-aspartate; OCD: Obsessive-compulsive disorder; PGx: Pharmacogenomic testing; SSRI: Selective serotonin reuptake inhibitors; TDM: Therapeutic drug monitoring; TRD: Treat-
\end{abstract} ment resistant depression; YBOCS: Yale-Brown obsessive-compulsive disorder.

\section{Acknowledgements}

We would like to pay our gratitude and our respects to our friend and colleague, Dr. Matteo Sibilla. After contributing to this paper, Dr. Matteo Sibilla passed away in August of 2021. He was a dedicated clinician, a passionate researcher and an outstanding colleague. He will be deeply missed.

\section{Authors' contributions}

$M M, N R, C F, P C, M L, M F, R C, S M$, and GL were responsible for clinical consultations, psychometric analyses, and esketamine administrations. BF, VN, and PA were responsible for pharmacogenetic analyses along with MM and KM for their interpretation. IS performed TDM analysis. Major contributors for writing the report were MM, PC, ML, MF, RC, GL, and $K M$. The final revision was made by $\mathrm{MM}, \mathrm{BB}, \mathrm{CA}, \mathrm{CE}, \mathrm{DA}$, and $\mathrm{CM}$. All authors read and approved the final manuscript.

\section{Funding}

This work has been supported by a grant ( $n^{\circ} 2019-3396$ to DA) from the Italian Cariplo Foundation, which had not any involvement in manuscript preparation, or decision to submit the article for publication.

\section{Declarations}

\section{Availability of data and materials}

The data sets generated and/or analysed during the current study are not publicly available due to privacy reasons.

\section{Ethics approval and consent to participate}

Written informed consent for the use of the anonymous clinical data was obtained.

\section{Consent for publication}

Written informed consent was obtained from the patient for publication of this case report. A copy of the written consent is available for review by the Editor-in-Chief of this journal.

\section{Competing interests}

The authors declare that they have no competing interests.

\section{Author details}

${ }^{1}$ Psychiatric Department, San Gerardo Hospital, ASST Monza, Monza, Italy. ${ }^{2}$ Department of Medicine and Surgery, University of Milano Bicocca, Monza, Italy. ${ }^{3}$ Faculty of Medicine, University Vita-Salute San Raffaele, Milan, Italy. ${ }^{4}$ Department of Pharmacology, Jessenius Faculty of Medicine in Martin, Comenius University in Bratislava, Martin, Slovakia. ${ }^{5}$ Psychiatry Unit, Department of Biomedical and Clinical Sciences "Luigi Sacco", University of Milan, Milan, Italy. ${ }^{6}$ CRC "Aldo Ravelli" for Neurotechnology and Experimental Brain Therapeutics, University of Milan, Milan, Italy. ${ }^{7}$ Cytogenetics and Medical Genetics Unit, Centre for Disorders of Iron Metabolism, San Gerardo Hospital, ASST Monza, Monza, Italy. ${ }^{8}$ Clinical Chemistry Laboratory, San Gerardo Hospital, ASST Monza, Monza, Italy.

Received: 31 May 2021 Accepted: 25 August 2021

Published online: 16 September 2021

\section{References}

1. Rehm J, Shield KD. Global burden of disease and the impact of mental and addictive disorders. Curr Psychiatry Rep. 2019;21(2):10.

2. GBD 2017 Disease and Injury Incidence and Prevalence Collaborators. Global, regional, and national incidence, prevalence, and years lived with disability for 354 diseases and injuries for 195 countries and territories, 1990-2017: a systematic analysis for the Global Burden of Disease Study 2017. Lancet. 2018;392(10159):1789-858.

3. Rush AJ, Trivedi MH, Wisniewski SR, Nierenberg AA, Stewart JW, Warden D, et al. Acute and longer-term outcomes in depressed outpatients requiring one or several treatment steps: a STAR*D report. Am J Psychiatry. 2006;163(11):1905-17.

4. Gaynes BN, Lux L, Gartlehner G, Asher G, Forman-Hoffman V, Green $J$, et al. Defining treatment-resistant depression. Depress Anxiety. 2020;37(2):134-45.

5. Papakostas Gl, lonescu DF. Towards new mechanisms: an update on therapeutics for treatment-resistant major depressive disorder. Mol Psychiatry. 2015;20(10):1142-50.

6. Bolhuis K, Mcadams TA, Monzani B, Gregory AM, Mataix-Cols D, Stringaris $\mathrm{A}$, et al. Aetiological overlap between obsessive-compulsive and 
depressive symptoms: a longitudinal twin study in adolescents and adults. Psychol Med. 2014;44(7):1439-49.

7. Denys D, Tenney N, van Megen HJGM, de Geus F, Westenberg HGM. Axis I and II comorbidity in a large sample of patients with obsessive-compulsive disorder. J Affect Disord. 2004;80(2-3):155-62.

8. Quarantini LC, Torres AR, Sampaio AS, Fossaluza V, de Mathis MA, do Rosário MC, et al. Comorbid major depression in obsessive-compulsive disorder patients. Compr Psychiatry. 2011;52(4):386-93.

9. de Almeida AG, Quarantini LC, Góis CR, Santos-Jesus R, Miranda-Scippa ÂMA, de Oliveira IR, et al. Obsessive-compulsive disorder: an open-label pilot trial of escitalopram. CNS Spectr. 2007;12(7):519-24.

10. McGrath PJ, Khan AY, Trivedi MH, Stewart JW, Morris DW, Wisniewski SR, et al. Response to a selective serotonin reuptake inhibitor (citalopram) in major depressive disorder with melancholic features: a STAR* D report. J Clin Psychiatry. 2008;69(12):1847-55.

11. Moritz S, Meier B, Hand I, Schick M, Jahn H. Dimensional structure of the Hamilton Depression Rating Scale in patients with obsessive-compulsive disorder. Psychiatry Res. 2004;125(2):171-80.

12. Rosenberg DR, Macmaster FP, Keshavan MS, Fitzgerald KD, Stewart CM, Moore GJ. Decrease in caudate glutamatergic concentrations in pediatric obsessive-compulsive disorder patients taking paroxetine. J Am Acad Child Adolesc Psychiatry. 2000;39(9):1096-103.

13. Rosenberg DR, Mirza Y, Russell A, Tang J, Smith JM, Banerjee SP, et al. Reduced anterior cingulate glutamatergic concentrations in childhood $\mathrm{OCD}$ and major depression versus healthy controls. J Am Acad Child Adolesc Psychiatry. 2004;43(9):1146-53.

14. Chakrabarty K, Bhattacharyya S, Christopher R, Khanna S. Glutamatergic dysfunction in OCD. Neuropsychopharmacology. 2005;30(9):1735-40.

15. Yücel M, Wood SJ, Wellard RM, Harrison BJ, Fornito A, Pujol J, et al. Anterior cingulate glutamate-glutamine levels predict symptom severity in women with obsessive-compulsive disorder. Aust N Z J Psychiatry. 2008;42(6):467-77.

16. Starck G, Ljungberg M, Nilsson $M$, Jönsson L, Lundberg S, Ivarsson T, et al. A $1 \mathrm{H}$ magnetic resonance spectroscopy study in adults with obsessive compulsive disorder: relationship between metabolite concentrations and symptom severity. J Neural Transm. 2008;115(7):1051-62.

17. Bhattacharyya S, Khanna S, Chakrabarty K, Mahadevan A, Christopher R, Shankar SK. Anti-brain autoantibodies and altered excitatory neurotransmitters in obsessive-compulsive disorder. Neuropsychopharmacology. 2009;34(12):2489-96.

18. Pittenger C, Bloch MH, Williams K. Glutamate abnormalities in obsessive compulsive disorder: neurobiology, pathophysiology, and treatment. Pharmacol Ther. 2011;132(3):314-32.

19. Hashimoto K. Rapid-acting antidepressant ketamine, its metabolites and other candidates: a historical overview and future perspective. Psychiatry Clin Neurosci. 2019;73(10):613-27.

20. Jelen LA, Young AH, Stone JM. Ketamine: a tale of two enantiomers. J Psychopharmacol. 2021;35(2):109-23.

21. Duman RS, Aghajanian GK, Sanacora G, Krystal JH. Synaptic plasticity and depression: new insights from stress and rapid-acting antidepressants. Nat Med. 2016;22(3):238-49.

22. Lener MS, Niciu MJ, Ballard ED, Park M, Park LT, Nugent AC, et al. Glutamate and gamma-aminobutyric acid systems in the pathophysiology of major depression and antidepressant response to ketamine. Biol Psychiatry. 2017:81(10):886-97.

23. Rodriguez Cl, Kegeles LS, Flood P, Simpson HB. Rapid resolution of obsessions after an infusion of intravenous ketamine in a patient with treatmentresistant obsessive-compulsive disorder. J Clin Psychiatry. 2011;72(4):567-9.

24. Bloch MH, Wasylink S, Landeros-Weisenberger A, Panza KE, Billingslea E, Leckman JF, et al. Effects of ketamine in treatment-refractory obsessivecompulsive disorder. Biol Psychiatry. 2012;72(11):964-70.

25. Rodriguez $\mathrm{Cl}$, Kegeles $\mathrm{LS}$, Levinson A, Feng T, Marcus SM, Vermes $D$, et al. Randomized controlled crossover trial of ketamine in obsessivecompulsive disorder: proof-of-concept. Neuropsychopharmacology. 2013;38(12):2475-83.

26. Sharma LP, Thamby A, Balachander S, Janardhanan CN, Jaisoorya TS, Arumugham SS, et al. Clinical utility of repeated intravenous ketamine treatment for resistant obsessive-compulsive disorder. Asian J Psychiatr. 2020;52: 102183.
27. American Psychiatric Association. Diagnostic and Statistical Manual of Mental Disorders, 5th ed. (DSM-5). 2013. https://doi.org/10.1176/appi. books.9780890425596

28. Franklin ME, Budzyn S, Freeman H. OCD Spectrum Disorders. In: Olatunji $\mathrm{BO}$, editor. The Cambridge handbook of anxiety and related disorders. Cambridge: Cambridge University Press; 2019. p. 603-23.

29. Doron G, Derby D, Szepsenwol O, Nahaloni E, Moulding R. Relationship obsessive-compulsive disorder: interference, symptoms, and maladaptive beliefs. Front Psychiatry. 2016;7:58.

30. Hiemke C, Bergemann N, Clement HW, Conca A, Deckert J, Domschke K, et al. Consensus guidelines for therapeutic drug monitoring in neuropsychopharmacology: update 2017. Pharmacopsychiatry. 2018;51 (1-02):9-62.

31. Stahl SM. L-methylfolate: a vitamin for your monoamines. J Clin Psychiatry. 2008;69(9):1352-3.

32. López-León S, Janssens ACJW, González-Zuloeta Ladd AM, Del-Favero J, Claes SJ, Oostra BA, et al. Meta-analyses of genetic studies on major depressive disorder. Mol Psychiatry. 2008;13(8):772-85.

33. Peerbooms OLJ, van Os J, Drukker M, Kenis G, Hoogveld L, de Hert M, et al. Meta-analysis of MTHFR gene variants in schizophrenia, bipolar disorder and unipolar depressive disorder: evidence for a common genetic vulnerability? Brain Behav Immun. 2011;25(8):1530-43.

34. Evinova A, Babusikova E, Straka S, Ondrejka I, Lehotsky J. Analysis of genetic polymorphisms of brain-derived neurotrophic factor and methylenetetrahydrofolate reductase in depressed patients in a Slovak (Caucasian) population. Gen Physiol Biophys. 2012;31(4):415-22.

35. Zanardi R, Serretti A, Rossini D, Franchini L, Cusin C, Lattuada E, et al. Factors affecting fluvoxamine antidepressant activity: influence of pindolol and 5-HTTLPR in delusional and nondelusional depression. Biol Psychiatry. 2001;50(5):323-30.

36. Arias B, Catalán R, Gastó C, Gutiérrez B, Fañanás L. 5-HTTLPR polymorphism of the serotonin transporter gene predicts non-remission in major depression patients treated with citalopram in a 12-weeks follow up study. J Clin Psychopharmacology. 2003;23(6):563-7.

37. Serretti A, Cusin C, Rossini D, Artioli P, Dotoli D, Zanardi R. Further evidence of a combined effect of SERTPR and TPH on SSRIs response in mood disorders. Am J Med Genet Neuropsychiatr Genet. 2004;129B(1):36-40.

38. Cervilla JA, Rivera M, Molina E, Torres-González F, Bellón JA, Moreno $B$, et al. The 5 -HTTLPR s/s genotype at the serotonin transporter gene (SLC6A4) increases the risk for depression in a large cohort of primary care attendees: the PREDICT-gene study. Am J Med Genet B Neuropsychiatr Genet. 2006;141B(8):912-7.

39. Luscher B, Shen Q, Sahir N. The GABAergic deficit hypothesis of major depressive disorder. Mol Psychiatry. 2011;16(4):383-406.

40. Gonda X, Sarginson J, Eszlari N, Petschner P, Toth ZG, Baksa D, et al. A new stress sensor and risk factor for suicide: the $T$ allele of the functional genetic variant in the GABRA6 gene. Sci Rep. 2017;7(1):12887.

41. Gonda X, Petschner P, Eszlari N, Sutori S, Gal Z, Koncz S, et al. Effects of different stressors are modulated by different neurobiological systems: the role of GABA-A versus $C B 1$ receptor gene variants in anxiety and depression. Front Cell Neurosci. 2019;13:138.

42. Pu M, Zhang Z, Xu Z, Shi Y, Geng L, Yuan Y, et al. Influence of genetic polymorphisms in the glutamatergic and GABAergic systems and their interactions with environmental stressors on antidepressant response. Pharmacogenomics. 2013;14(3):277-88.

43. Tran AX, Ho TT, Varghese GS. Role of CYP2B6 pharmacogenomics in bupropion-mediated smoking cessation. J Clin Pharm Ther. 2019;44(2):174-9

44. Pittenger $\mathrm{C}$, Bloch MH. Pharmacological treatment of obsessive-compulsive disorder. Psychiatr Clin North Am. 2014;37(3):375-91.

45. Kayser RR. Pharmacotherapy for treatment-resistant obsessive-compulsive disorder. J Clin Psychiatry. 2020;81(5): 19ac13182.

46. Tosta CL, Silote GP, Fracalossi MP, Sartim AG, Andreatini R, Joca SRL, et al. S-ketamine reduces marble burying behaviour: involvement of ventromedial orbitofrontal cortex and AMPA receptors. Neuropharmacology. 2019;144:233-43.

\section{Publisher's Note}

Springer Nature remains neutral with regard to jurisdictional claims in published maps and institutional affiliations. 